\title{
Correction to: Effects of moisture content on explosion characteristics of incense dust in incense factory
}

\author{
Shun-Chieh Chang ${ }^{1} \cdot$ Yu-Chi Cheng ${ }^{2} \cdot$ Xin-Hai Zhang $^{3} \cdot$ Chi-Min Shu $^{1}$ (D)
}

Published online: 15 June 2021

๑) Akadémiai Kiadó, Budapest, Hungary 2021

\section{Correction to: Journal of Thermal Analysis and Calorimetry https://doi.org/10.1007/s10973-021-10588-7}

The article Effects of moisture content on explosion characteristics of incense dust in incense factory, written by Shun-Chieh Chang, Yu-Chi Cheng, Xin-Hai Zhang, Chi-Min Shu, was originally published online on the publisher's internet portal on March 15, 2021 with Open Access under a Creative Commons Attribution (CC BY) license 4.0. With the author's/authors' decision to cancel Open Access the copyright of the article changed on May 6, 2021 to (C) Akadémiai Kiadó, Budapest, Hungary 2021 with all rights reserved.

The original article has been corrected.

Publisher's Note Springer Nature remains neutral with regard to jurisdictional claims in published maps and institutional affiliations.

The original article can be found online at https://doi.org/10.1007/ s10973-021-10588-7.

Chi-Min Shu

shucm@yuntech.edu.tw

1 Department of Safety, Health, and Environmental Engineering, National Yunlin University of Science and Technology (YunTech), 123, University Rd., Sec. 3, Douliou 64002, Yunlin, Taiwan, ROC

2 Graduate School of Engineering Science and Technology, YunTech, 123, University Rd., Sec. 3, Douliou 64002, Yunlin, Taiwan, ROC

3 College of Safety and Engineering, Xi' an University of Science and Technology, Xi' an, China 